\title{
PELATIHAN PENGELOLAAN E-COMMERCE PADA YAYASAN PONDOK PESANTREN AL-HIKMAH MANGUNREJA KABUPATEN TASIKMALAYA
}

\author{
Sulidar Fitri, Muhammad Taufiq, Hani Rubiani, R. Apip Miptahudin \\ Universitas Muhammadiyah Tasikmalaya \\ sfitri@umtas.ac.id
}

\begin{abstract}
Society must be able to follow the rhythm of the times when the era of modernization is developed rapidly, especially in terms of information technology so that people must have sufficient knowledge and insight to co-exist with the era of the all-electronic as status quo. In this case, e-commerce becomes one of the easiest alternatives to support someone in entrepreneurship. Through the E-Commerce Management Training at the Al-hikmah Mangunreja boarding school foundation in Tasikmalaya Regency, which has been organized by the Muhammadiyah University of Tasikmalaya, it can provide knowledge and skills for the people sheltered by the Al-Hikmah Foundation, specifically the use of e-commerce to be able to compete in global business. The training participants from the Al-Hikmah Foundation were very enthusiastic in participating in these activities and had high expectations of participants so that service activities such as e-commerce training could be carried out on an ongoing basis and by providing diverse material in an effort to improve the ability of the community towards a prosperous society. The highest percentage obtained by $90 \%$ from the evaluation results of participants who agreed stated that the training is useful to add insight into e-commerce. Another $90 \%$ is found in statements that agree that social media as a business promotion is easy. Statements with the lowest percentage occur at half of the number of participants, 50\% which states that Creating a promotional blog with wordpress is easy.
\end{abstract}

Keywords: E-commerce management training; Al-Hikmah Foundation; Information Technology

\begin{abstract}
Abstrak
Masyarakat harus mampu mengikuti ritme perkembangan zaman dimana era modernisasi sangat berkempang pesat terutama dari sisi teknologi informasi sehingga masyarakat harus memiliki pengetahuan dan wawasan yang cukup untuk berdampingan dengan zaman yang serba elektronik seperti sekarang ini. Dalam hal ini e-commerce menjadi salah satu alternatif yang paling mudah untuk mendukung seseorang berwirausaha. Melalui Pelatihan Pengelolaan ECommerce pada yayasan pondok pesantren Al-hikmah Mangunreja Kabupaten Tasikmalaya yang telah diselenggarakan oleh Universitas Muhammadiyah Tasikmalaya dapat memberikan pengetahuan dan keterampilan bagi masyarakat yang dinaungi oleh Yayasan Al-Hikmah khususnya pemanfaatan e-commerce agar mampu bersaing dalam bisnis global. Peserta pelatihan dari Yayasan Al-Hikmah sangat antusias dalam mengikuti kegiatan tersebut dan besar harapan peserta agar kegiatan pengabdian seperti pelatihan e-commerce dapat dilaksanakan secara berkesinambungan dan dengan pemberian materi yang beragam dalam upaya meningkatkan kemampuan masyarakat menuju masyarakat yang sejahtera. Angka prosentase didapatkan paling tinggi sebesar $90 \%$ dari hasil evaluasi peserta yang setuju menyatakan bahwa Pelatihan bermanfaat menambah wawasan mengenai e-commerce. $90 \%$ lainnya didapatkan pada statement yang menyatakan setuju bahwa Sosial media sebagai promosi bisnis adalah mudah. Pernyataan dengan prosentasi terendah terjadi sebesar setengah dari jumlah peserta yaitu $50 \%$ yang menyatakan bahwa Membuat blog promosi dengan wordpress adalah mudah.
\end{abstract}

Kata Kunci: Pelatihan pengelolaan e-commerce; Yayasan Al-Hikmah; Teknologi Informasi

Submitted: 2020-07-27 Revised: 2020-09-03 Accepted: 2020-09-04 


\section{Pendahuluan}

Perpindahan era dari dunia fisik ke dalam dunia digital atau sering disebut sebagai digitalisasi era, memaksa para pebisnis untuk meningkatkan proses transaksi dalam bisnis ke dalam bentuk elektronik agar tetap kompetitif dalam persaingan bisnis di masa era revolusi industri 4.0. Seiring dengan Perkembangan Teknologi Informasi di era revolusi 4.0 saat ini tidak menutup kemungkinan perlu untuk menyikapi secara serius terhadap penggalian potensi sumber daya manusia baik pada taraf kemandirian berwirausaha sehingga menuntut teknologi untuk mampu mengikuti tingkat kebutuhan masyarakat terhadap permasalahan yang terjadi selama ini(Taufiq \& Fitri, 2020). Urgensi dari revolusi tersebut perlu disikapi secara serius untuk penggalian potensi masyarakat baik pada taraf literasi teknologi informasi.

Aktifitas transaksi bisnis melalui media elektronik (e-commerce) sangat memudahkan bagi masyarakat dimana informasi penting dan kebaruan terkini yang disajikan bisa dengan sangat mudah dan cepat didapatkan oleh konsumen informasi(Maulana \& Susilo, 2015). Dalam hal ini, masyarakat juga harus mampu mengikuti ritme perkembangan zaman dimana era modernisasi sangat berkempang pesat terutama dari sisi teknologi informasi sehingga masyarakat harus memiliki pengetahuan dan wawasan yang cukup untuk berdampingan dengan zaman yang serba elektronik seperti sekarang ini.

Pada era pasar bebas seperti sekarang ini, masyarakat memiliki beberapa alternatif untuk bisa bersaing dalam hal bisnis perseorangan untuk bisa bertahan hidup. Dalam hal ini e-commerce menjadi salah satu alternatif yang paling mudah untuk mendukung seseorang berwirausaha(Rahayu \& Laela, 2018). Banyak aplikasi yang ditawarkan sebagai lapak untuk menaungi usaha mandiri perseorang bagi masyarakat yang ingin berwirausaha dan tidak memandang usia maupun latar belakang pekerjaan seseorang sehingga dapat mendukung persaingan sampai ke tingkat global. Materi mengenai penggambaran teknologi informasi berupa e-commerce yang dapat berintegrasi dengan sosial media juga sangat dibutuhkan karena membuat masyarakat jadi lebih sadar untuk terus mengembangkan diri dari sisi ilmu pengetahuan dan informasi(Rubiani et al., 2020).

Pondok pesantren Al-Hikmah tepatnya berlokasi di daerah Kecamatan Mangunreja, Kabupaten Tasikmalaya. Lebih spesifiknya beralamatkan di Jl. Kaum Selatan No. 188 04/01 Desa Mangunreja dimana lokasi tersebut tidak terlalu jauh dari Kampus Universitas Muhammadiyah Tasikmalaya. Pesantren ini berdiri di bawah naungan Yayasan Al-Hikmah yang berlokasi satu area dengan Pondok Pesantren Al-Hikmah. Saat ini Pondok pesantren tersebut dipimpin oleh Bapak Abdu malik Ibrahim, SHI.

Melalui Pelatihan Pengelolaan E-Commerce pada yayasan pondok pesantren Alhikmah Mangunreja Kabupaten Tasikmalaya yang telah diselenggarakan oleh Universitas Muhammadiyah Tasikmalaya dapat memberikan pengetahuan dan keterampilan bagi masyarakat yang dinaungi oleh Yayasan Al-Hikmah khususnya pemanfaatan e-commerce agar mampu bersaing dalam bisnis global. Peserta pelatihan dari Yayasan Al-Hikmah sangat antusias dalam mengikuti kegiatan tersebut dan besar harapan peserta agar kegiatan pengabdian seperti pelatihan e-commerce dapat dilaksanakan secara 
berkesinambungan dan dengan pemberian materi yang beragam dalam upaya meningkatkan kemampuan masyarakat menuju masyarakat yang sejahtera.

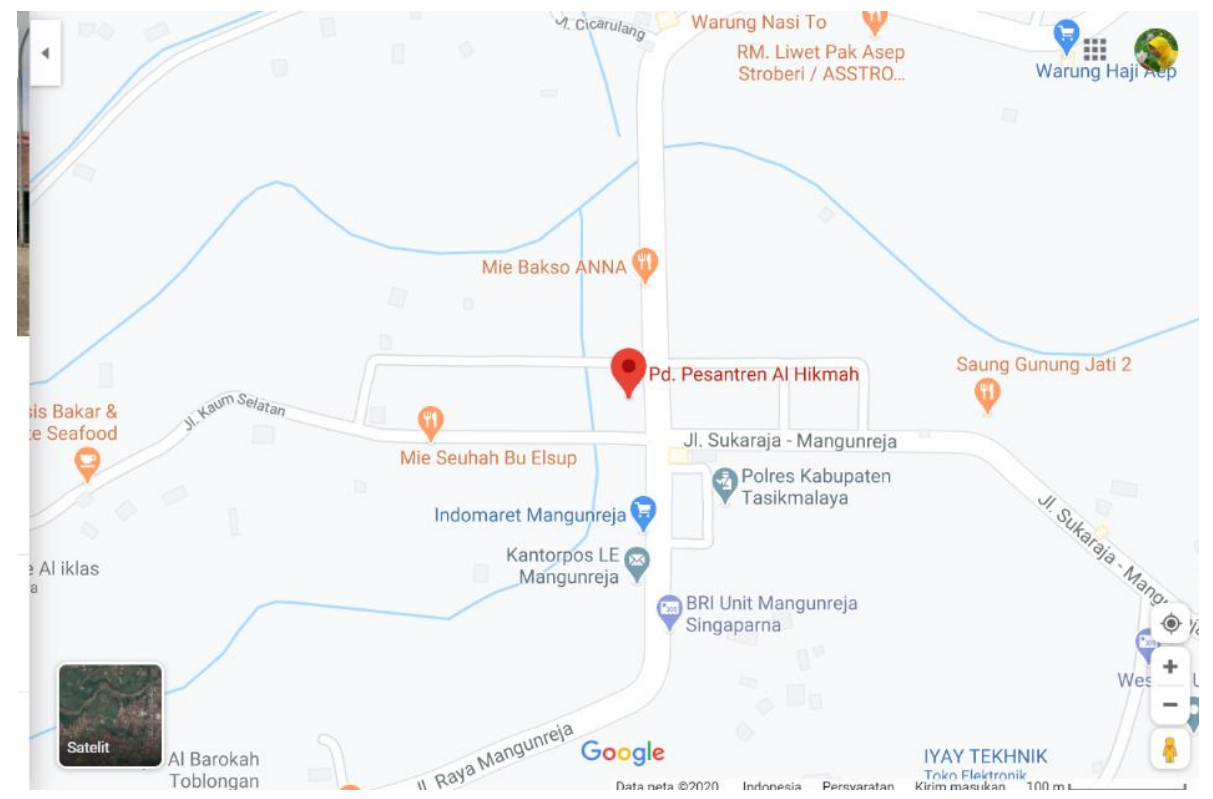

Gambar 1. Peta Lokasi Yayasan Al-Hikmah

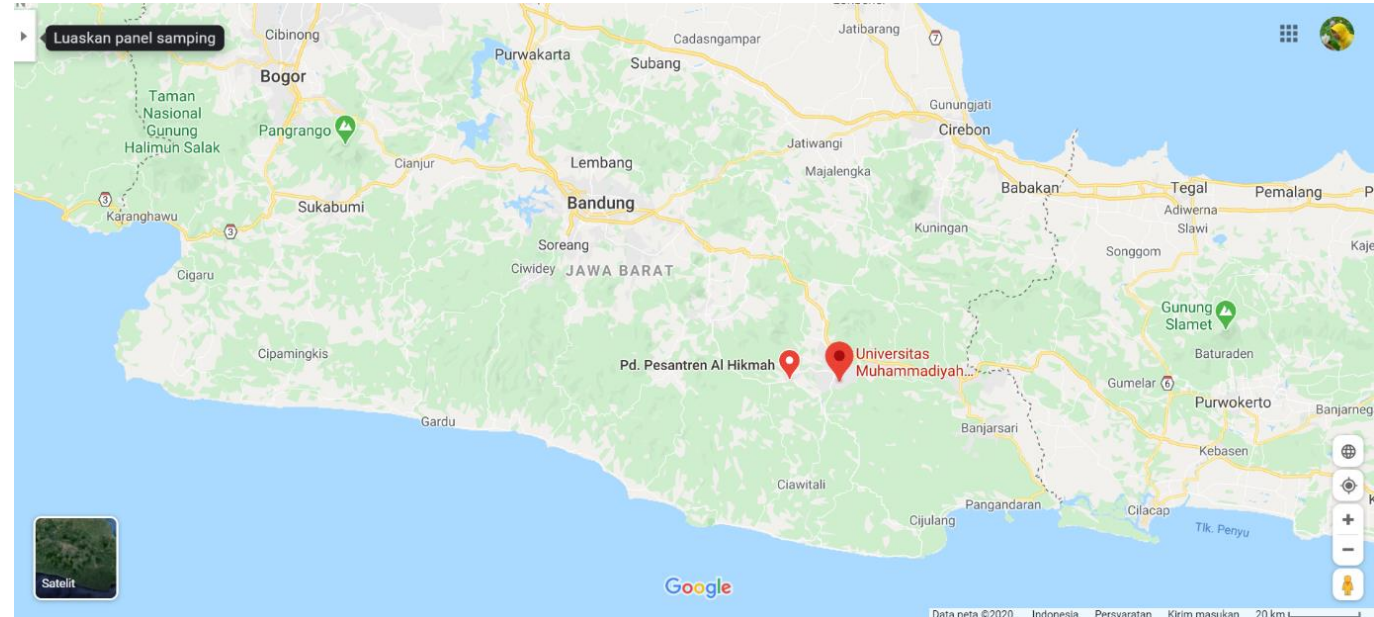

Gambar 2. Lokasi Geografis Yayasan Al-Hikmah pada google maps

Secara geografis, Pondok Pesantren Al-Hikmah terletak di pinggiran kota Tasikmalaya yaitu wilayah Kabupaten Tasikmalaya. Pada wilayah kabupaten ini, belum terdapat pusat berbelanjaan besar seperti mall yang memiliki fasilitas lebih banyak dibandingkan pasar dan disamping itu, karakteristik masyarakatnya juga belum banyak yang terbiasa dengan pemasaran maupun berbelanja secara online.

\section{Metode}

Sasaran dari pelaksanaan kegiatan pelatihan ini adalah seluruh Sumber Daya Manusia (SDM) yang ada pada Yayasan Al-Hikmah dan Pondok Pesantren Al-Hikmah. Para Peserta terdiri dari tenaga pendidik dan pengajar, serta para pengelola Yayasan maupun Pondok Pesantren Al-Hikmah. Tempat yang digunakan untuk melakukan kegiatan yaitu 
bertempat di aula yang biasa digunakan untuk pengajian rutin para pengelola di Yayasan Al-Hikmah tersebut.

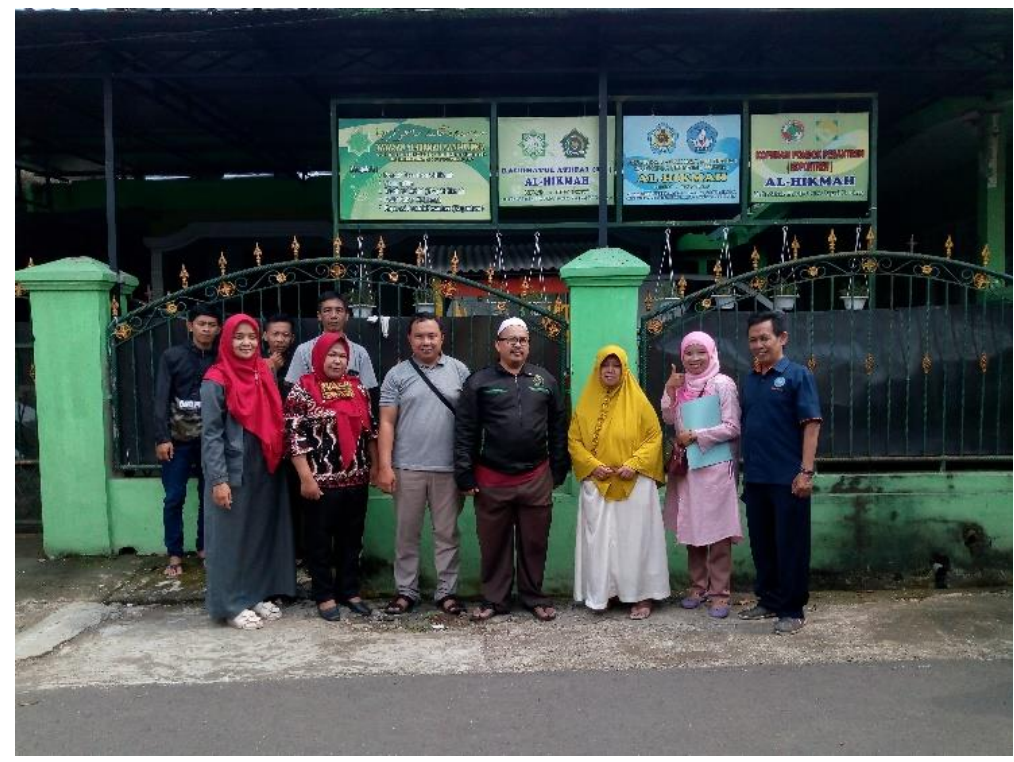

Gambar 3. Depan kantor Yayasan Al-Hikmah

Pelaksanaan kegiatan Pengabdian Kepada Masyarakat berupa pemberian ceramah atau penyuluhan didalam aula, dimulai jam 13.00, selama 3 jam, diisi oleh team dari dosen UMTAS, disamping ceramah juga dilakukan diskusi dan prakter cara pemanfaatan aplikasi tentang bencana berbasis Teknologi Informasi. Perangkat yang digunakan yaitu proyektor untuk penyampaian materi oleh tim dosen UMTAS sebagai pemateri. Sedangkan para peserta menggunakan smartphone masing-masing yang sedang dibawa untuk melakukan praktek pengelolaan e-commerce.

Dalam penyampaian materi pelatihan dilakukan dalam 3 tahap. Tahap pertama berisi gambaran umum pengenalan teknologi informasi yang terjadi dalam era revolusi industri 4.0. Materi ini berisi mengenai kebutuhan masyarakat akan internet yang sudah mulai menjadi kebutuhan primer. Banyaknya transaksi jual bisnis perdagangan menggabungkan konsep toko offline dengan toko online.

Tahap berikutnya yaitu tahap sesi kedua, berisi pengenalan aplikasi-aplikasi dalam smartphone yang mendukung pelaksanaan e-commerce bahkan untuk kebutuhan individu. Beberapa diantaranya seperti membuat web Blog sederhana untuk bisnis, Bukalapak, Tokopedia, Lazada, JDid, Shopee, bahkan aplikasi untuk kebutuhan promosi seperti Whatsapp, Instagram, dan facebook sebagai pendukung implementasi untuk ecommerce.

Tahapan terakhir yaitu Bersama-sama mempraktekan pembuatan akun untuk mengelola bisnis pribadi dalam level pemula menggunakan aplikasi pendukung yang ada di smartphone mereka masing-masing. Praktek pembuatan akun ini membuat mereka antusias karena ternyata pembuatan akun untuk menjadi seorang wirausaha secara individu dalam hal ini sebagai pedagang sangatlah mudah. Bahkan peserta melakukan beberapa percobaan untuk melakukan belanja online sebagai bentuk Latihan diri dalam keterbukaan terhadap teknologi yang mereka anggap baru. Tidak banyak dari peserta 
yang paham mengenai applikasi e-commerce kemudian membuka diri untuk barani mencoba dan kemudian sangat antusias.

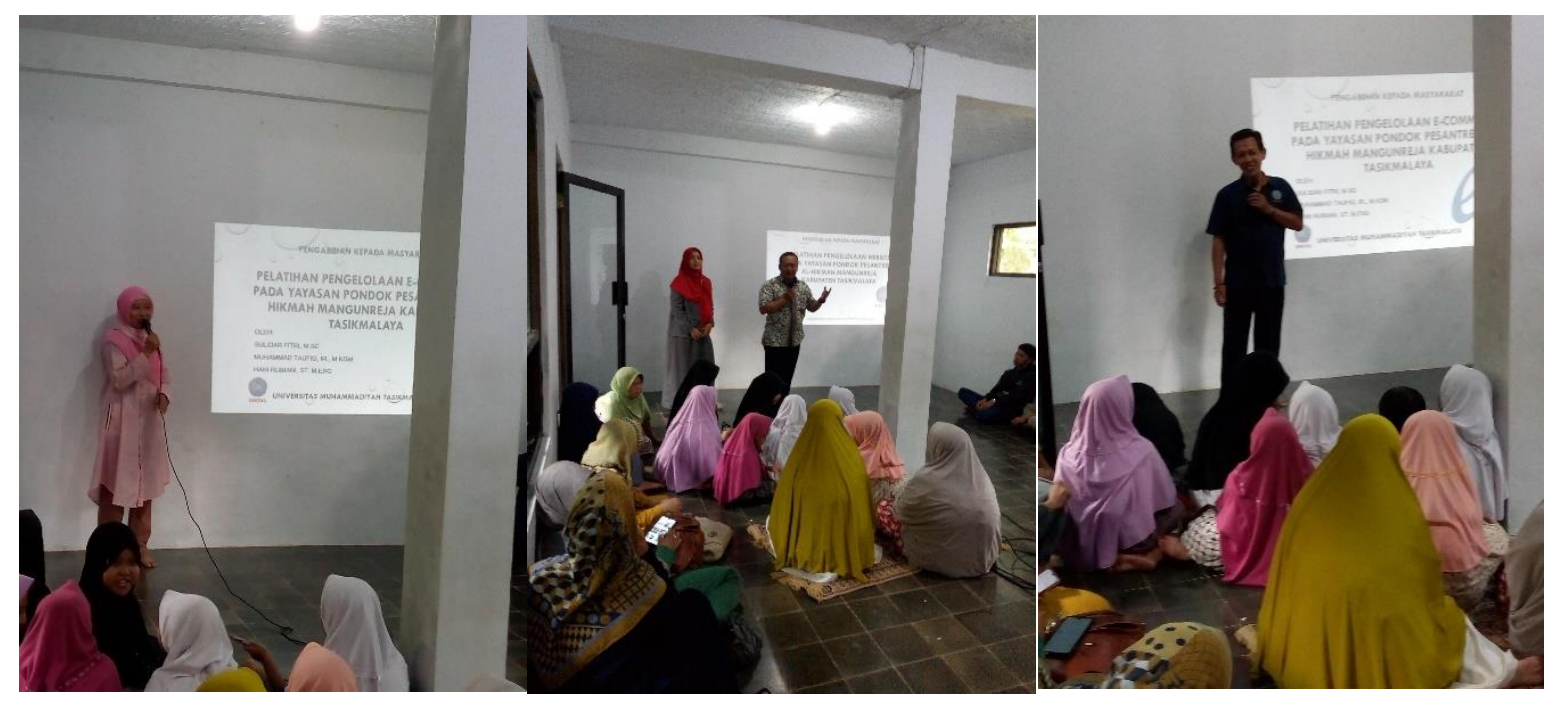

Gambar 4. Suasana pelatihan saat sedang berlangsung

\section{Hasil dan Pembahasan}

Setelah sesi pengisian materi yang telah dilakukan, maka dilakukan tahap selanjutnya yaitu evaluasi dan monitoring. Maka rekomendasi yang kami ajukan bagi kegiatan ini bahwa kegiatan serupa seharusnya dilaksanakan secara kontinyu untuk meningkatkan pengetahuan dan kewaspadaan para peserta terutama mengenai pentingnya wawasan tentang teknologi infomrasi. Perlunya diadakan kerjasama dengan instansi yang memiliki pengalaman dalam hal e-commerce atau pelaku usaha di bidang teknologi informasi. Selain mengisi kegiatan pelatihan dengan memberikan pemaparan mengenai konsep dasar secara umum mengenai bisnis dalam penggunaan teknologi informasi, kegiatan ini juga dilakukan pembagian selebaran yang berisi informasi singkat dari materi yang telah dipaparkan beserta angket dari tim pengabdian masyarakat UMTAS untuk mengetahui hasil evaluasi secara deskriptif dampak dari sosialisasi yang telah dilakukan.

Selama kegiatan pelatihan berlangsung terlihat wajah-wajah antusias dari para peserta yang mengikuti pemaparan yang diberikan. Sesekali beberapa peserta dari yang berusia muda hingga berusia paruh baya menanyakan hal-hal yang dianggap menarik seperti pentingnya wawasan teknologi informasi dalam hal e-commerce.

Kegiatan pelatihan ini mendapat sambutan yang sangat baik, berdasarkan hasil wawancara dengan peserta mengenai tanggapan mereka atas terselenggaranya kegiatan sosialisasi ini diperoleh hal-hal sebagai berikut :

1. Materi yang disampaikan oleh tim pengabdian masyarakat dari Universitas Muhammadiyah Tasikmalaya sangat menarik dan para peserta merasa mendapatkan wawasan tambahan mengenai perkembangan dunia teknologi informasi di era industry 4.0 yang sedang terjadi di masa sekarang ini. 
2. Kegiatan pelatihan oleh peserta dinilai sangat bermanfaat sehingga mereka mengharapkan agar ada kegiatan lanjutan yang berkaitan dengan Dunia teknologi informasi.

3. Perkembangan teknologi dalam dunia bisnis dan transaksi bisnis yang sangat pesat membuat mereka jadi lebih sadar untuk terus mengembangkan diri dari sisi ilmu pengetahuan dan informasi.

4. Para peserta merasa harus lebih siap dalam menghadapi perubahan apapun secara global dan memeprsiapkan diri dalam mensikapi perubahan tersebut.

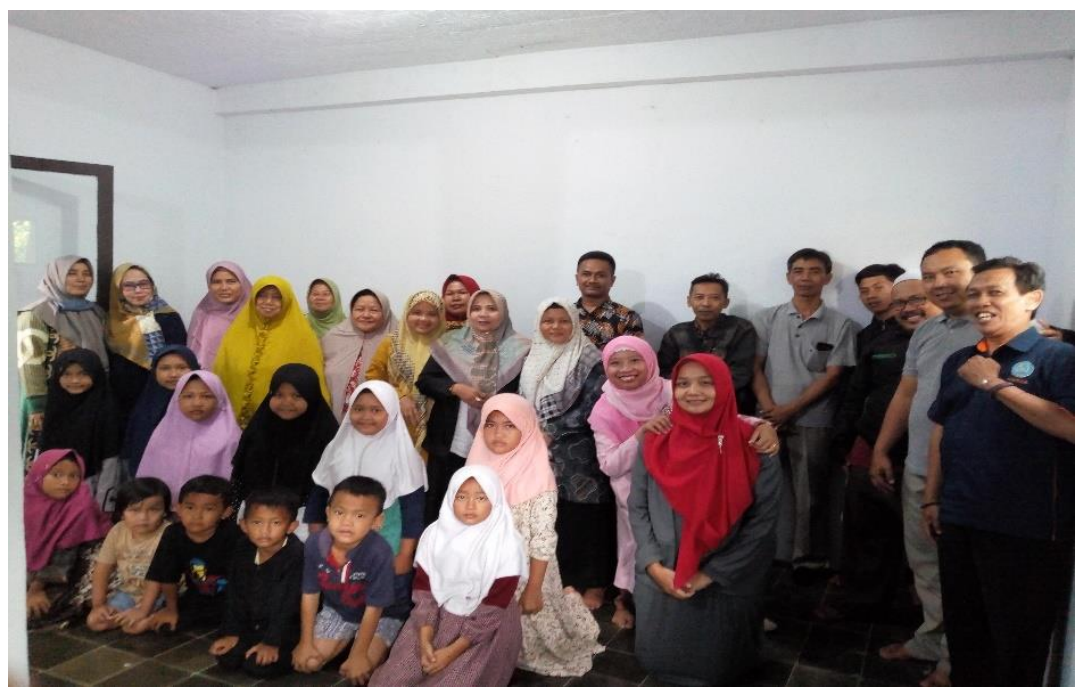

Gambar 5. Foto bersama di akhir kegiatan

Selain hasil wawancara kepada para peserta, terdapat hasil survey dengan menggunakan angket setelah dilaksanakannya kegiatan pelatihan tersebut. Data yang dikoleksi sebanyak 20 orang peserta yang telah mengikuti pelatihan. Dari gambar 1 bisa dilihat bahwa angka prosentase mengacu pada hasil koleksi data dari angket yang disebar pada para peserta setelah mengikuti kegiatan pelatihan.

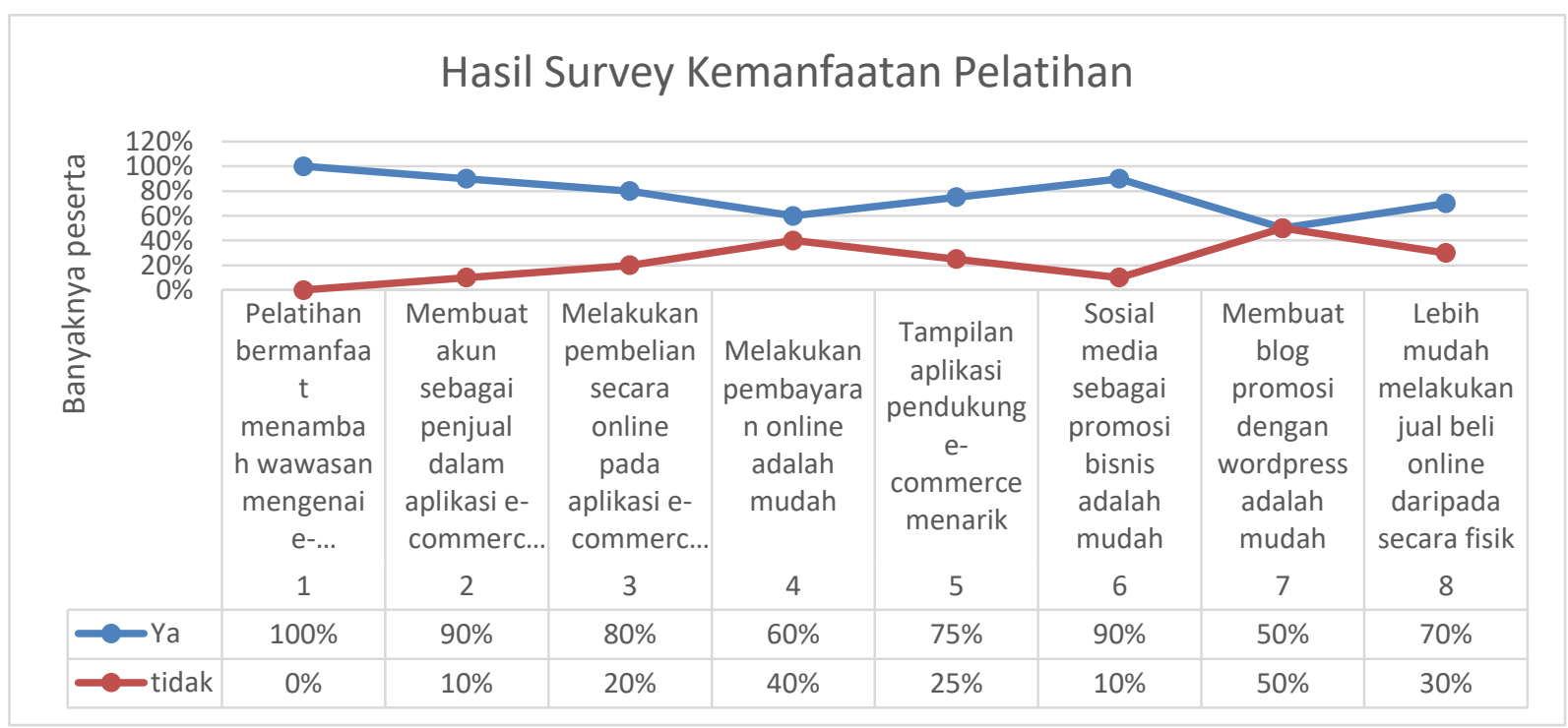

Gambar 6. Hasil evaluasi kegiatan 
Angka prosentase didapatkan paling tinggi pada statement no. 2 dan 6 dimana $90 \%$ peserta setuju menyatakan bahwa Pelatihan bermanfaat menambah wawasan mengenai e-commerce. 90\% lainnya didapatkan pada statement yang menyatakan setuju bahwa Sosial media sebagai promosi bisnis adalah mudah. Pernyataan dengan prosentasi terendah terjadi sebesar setengah dari jumlah peserta yaitu $50 \%$ yang menyatakan bahwa Membuat blog promosi dengan wordpress adalah mudah. Berdasarkan angka tersebut memperlihatkan bahwa dari beberapa praktikum yang telah dilakukan menunjukan tingkat kesulitan peserta lebih banyak terjadi pada materi pembuatan akun blog wordpress sebagai media untuk promosi bisnis.

\section{Kesimpulan}

Kesimpulan yang didapat setelah melaksanakan kegiatan adalah:

1. Kegiatan pengabdian kepada masyarakat mengenai pelatihan pengelolaan ecommerce ini telah terlaksana dengan baik.

2. Kegiatan pengabdian kepada masyarakat mengenai pelatihan pengelolaan ecommerce respon yang antusias dari para peserta yang merupakan Para Pendidik dan pengajar, anggota masyarakat yang dinaungi oleh Yayasan, serta para pengelola Yayasan.

3. Didapatkan beberapa pertanyaan dari peserta terkait materi pelatihan dari peserta mengharapkan ada kegiatan penyuluhan kembali terkait pengelolaan e-commerce

Kegiatan sudah terlaksana dengan baik namun masih ada kekekurangan yang perlu diperbaiki kedepannya. Hal yang menjadi kekurangan kegiatan ini adalah belum bisa memfasilitasi para peserta dengan perangkat gadget dengan spesifikasi tinggi dan belum bisa menyediakan jaringan internet dengan kecepatan yang maksimal dan rata untuk para peserta. Mereka masih menggunakan fasilitas paket kuota data masing-masing yang mana dalam hal ini memiliki kecepatan yang berbeda-beda atau bahkan ada yang kehabisan paket data sehingga butuh share tethering ke rekan lainnya. Harapan kedepannya semoga dapat mengadakan kegiatan pelatihan dengan fasilitas yang lebih baik.

\section{Daftar Pustaka}

Maulana, S. M., \& Susilo, H. (2015). Implementasi E-Commerce Sebagai Media Penjualan Online. Jurnal Administrasi Bisnis, 29(1), 9.

Pd. Pesantren Al Hikmah. (2020, July 27). Pd. Pesantren Al Hikmah. https://www.google.com/maps/place/Pd.+Pesantren+Al+Hikmah,+Mangunreja,+Ke c.+Mangunreja,+Tasikmalaya,+Jawa+Barat+46462/@7.3652895,108.0993176,17z/data=!3m1!4b1!4m5!3m4!1s0x2e6f55ac80501a6f:0xe3 736cedec36228c!8m2!3d-7.3652506!4d108.1015489?hl=id

Rahayu, E. S., \& Laela, S. (2018). Pengaruh Minat Berwirausaha Dan Penggunaan Sosial Media Terhadap Kewirausahaan Mahasiswa. Jurnal Pengembangan Wiraswasta, 20(3), 203. https://doi.org/10.33370/jpw.v20i3.246

Rubiani, H., Samsoleh, E., Fitri, S., \& Taufiq, M. (2020). Sosialisasi Sistem Informasi Kebencanaan Untuk Smp Dan Sma Di Kabupaten Pangandaran. 3(1), 6.

Taufiq, M., \& Fitri, S. (2020). Pelatihan Manajemen Potensi Berprestasi Di Era Revolusi Industri 4.0 Untuk Para Guru Dan Siswa Di Kabupaten Pangandaran. 3(1), 12. 